\title{
Efficacy and safety of insulin glargine added to a fixed-dose combination of metformin and a dipeptidyl peptidase- 4 inhibitor: results of the GOLD observational study
}

\author{
This article was published in the following Dove Press journal: \\ Vascular Health and Risk Management \\ 12 November 2013 \\ Number of times this article has been viewed
}

\section{Jochen Seufert ${ }^{1}$ \\ Katrin Pegelow ${ }^{2}$ \\ Peter Bramlage ${ }^{3}$}

'Division of Endocrinology and Diabetology, Department of Internal Medicine II, University Hospital of Freiburg, Freiburg, ${ }^{2}$ Sanofi Aventis Deutschland $\mathrm{GmbH}$, Berlin, ${ }^{3}$ Institut für Pharmakologie und Präventive Medizin, Mahlow, Germany
Correspondence: Jochen Seufert Division of Endocrinology and Diabetology, Department of Internal Medicine II, University Hospital of Freiburg, Freiburg, Hugstetter Str 55, 79106 Freiburg, Germany

Tel +4976127036340

Fax $+4976 \mid 27034130$

Email jochen.seufert@uniklinik-freiburg.de
Background: For patients with type 2 diabetes who are uncontrolled on a combination of two oral antidiabetic agents, addition of the long-acting basal insulin glargine is a well established treatment option. However, data on the efficacy and safety of a combination of metformin, a dipeptidyl peptidase-4 (DPP-4) inhibitor, and insulin glargine are limited in real-world settings. Therefore, the aim of this study was to analyze blood glucose control, rates of hypoglycemia and body weight in a large cohort of patients with type 2 diabetes treated with this combination therapy in real practice.

Methods: This noninterventional, multicenter, prospective, observational trial with a follow-up of 20 weeks enrolled insulin-naïve patients who had been on a stable fixed dose of metformin and a DPP-4 inhibitor for at least 3 months, and had a glycosylated hemoglobin $\left(\mathrm{HbA}_{1 \mathrm{c}}\right)$ between $7.5 \%$ and $10 \%$. Patients were selected at the investigators' discretion for initiation of insulin glargine at baseline. A total of 1,483 patients were included, of whom 1,262 were considered to be the efficacy set. Primary efficacy parameters were $\mathrm{HbA}_{1 \mathrm{c}}$ and fasting plasma glucose. Secondary outcome measures included achievement of glycemic targets, body weight, rates of hypoglycemia, and other safety parameters, as well as resource consumption.

Results: Upon initiation of insulin glargine, mean $\mathrm{HbA}_{1 \mathrm{c}}$ decreased from $8.51 \%$ to $7.36 \%$ $(-1.15 \% \pm 0.91 \%$; 95\% confidence interval [CI] -1.20 to -1.10$)$. An $\mathrm{HbA}_{1 \mathrm{c}}$ level $<6.5 \%$ was achieved in $8.2 \%$ of patients and a level $<7.0 \%$ in $31.5 \%$. Mean fasting plasma glucose decreased from $174 \pm 47 \mathrm{mg} / \mathrm{dL}$ to $127 \pm 31 \mathrm{mg} / \mathrm{dL}(-47.3 \pm 44.1 \mathrm{mg} / \mathrm{dL} ; 95 \% \mathrm{CI}-49.8$ to -44.8$)$. In $11.9 \%$ of patients, a fasting plasma glucose level $<100 \mathrm{mg} / \mathrm{dL}$ was achieved. Bodyweight decreased on average by $0.98 \pm 3.90 \mathrm{~kg}$ (95\% CI 1.19-0.76). Hypoglycemia (blood glucose $\leq 70 \mathrm{mg} / \mathrm{dL}$ ) was observed in 29 patients $(2.30 \%)$, of whom six $(0.48 \%)$ had nocturnal hypoglycemia and four $(0.32 \%)$ had documented severe events (blood glucose $<56 \mathrm{mg} / \mathrm{dL}$ ).

Conclusion: The results of this observational study show that insulin glargine, when added to a fixed-dose combination of metformin and a DPP-4 inhibitor, resulted in a significant and clinically relevant improvement of glycemic control. Importantly, this intervention did not interfere with the action of the DPP-4 inhibitors, resulting in neutral effects on weight and low rates of hypoglycemia. We conclude that this treatment intensification approach may be useful, efficient, and safe in daily clinical practice for patients with type 2 diabetes.

Keywords: diabetes, dipeptidyl dipeptidase-4 inhibitors, metformin, insulin glargine

\section{Introduction}

A fixed-dose combination of metformin and a dipeptidyl peptidase-4 (DPP-4) inhibitor has been shown to be an effective and particularly safe and convenient treatment strategy. ${ }^{1,2}$ 
In patients who do not reach their individual target glycosylated hemoglobin $\left(\mathrm{HbA}_{1 \mathrm{c}}\right)$ or fasting plasma glucose levels using this combination, adding a long-acting insulin (analog) is an attractive option for treatment escalation because of the combination of complementary effects of long-acting insulin and incretin-based therapies on fasting and postprandial glucose and consequently $\mathrm{HbA}_{1 \mathrm{c}} \cdot{ }^{3-5}$

A recent study by Arnolds et $\mathrm{al}^{6}$ performed in 48 subjects investigated whether addition of sitagliptin $100 \mathrm{mg} /$ day to an existing treatment of insulin glargine titrated to achieve fasting plasma glucose $\leq 100 \mathrm{mg} / \mathrm{dL}$ and/or metformin results in improved blood glucose control. Reduced 6-hour postprandial glucose excursions were found $(612 \pm 133 \mathrm{mg} / \mathrm{dL}$ per hour with the triple combination versus $728 \pm 132 \mathrm{mg} / \mathrm{dL}$ per hour with insulin glargine/metformin, $P=0.0008$ ). The triple combination was safe, and hypoglycemia rates (no major hypoglycemia) were generally low and comparable between the groups. Hollander et $\mathrm{al}^{3}$ evaluated the efficacy and safety of insulin detemir added to an existing treatment with metformin/sitagliptin compared with metformin/sitagliptin with or without sulfonylurea. Reductions in $\mathrm{HbA}_{1 \mathrm{c}}(-1.44 \%$ versus $-0.89 \%, P<0.001)$ and fasting plasma glucose $(-3.7$ versus $-1.2 \mathrm{mmol} / \mathrm{L}, P<0.001)$ were larger in the insulin detemir group, with no differences in weight changes and no episodes of major hypoglycemia.

These reports prompted us to investigate whether the results of these studies could be reproduced in a clinical practice setting where patients do not necessarily match those of randomized, controlled trials. ${ }^{7}$ For treatment escalation, we used insulin glargine, a long-acting insulin analog, as a proven flexible and efficient therapeutic option ${ }^{8,9}$ with a low risk of hypoglycemia. ${ }^{10}$ We added insulin glargine to a treatment regimen of metformin and a DPP-4 inhibitor established for at least 3 months in patients with an $\mathrm{HbA}_{1 \mathrm{c}}$ that remained elevated $(7.5 \%-10 \%)$. This observational study had two principal objectives: to document glycemic efficacy $\left(\mathrm{HbA}_{1 \mathrm{c}}\right)$, fasting plasma glucose, and insulin glargine doses used between baseline and the end of 20 weeks of follow-up; and to investigate the safety and tolerability of initiating insulin glargine in these patients.

\section{Materials and methods}

GOLD (Blood glucose reGulatiOn with Lantus ${ }^{\circledR}$ and a DPP-4 inhibitor in basal supported oral therapy [BOT] in type 2 diabetes patients) was a noninterventional, noncontrolled, multicenter, prospective observational study. The study was carried out in accordance with \$67(6) of the German Medicines Law (Arzneimittelgesetz, AMG), which does not allow stipulation of particular treatments or procedures, but monitoring of treatment decisions. It was announced to the Federal Institute of Drugs and Medical Devices (BfArM), the German Medical Association (Kassenärztliche Bundesvereinigung), and the head organizations of health insurance funds as necessary. The protocol of the study was approved by the ethics committee of the Berlin Chamber of Physicians on November 3, 2010. Patients had to provide written informed consent prior to enrolment.

\section{Patients}

Patients with type 2 diabetes mellitus were included in this observational trial, provided that they were at least 18 years old, had an $\mathrm{HbA}_{1 \mathrm{c}}$ between $7.5 \%$ and $10 \%$, had taken a combination of metformin and any DPP-4 inhibitor (agents used not specified) for at least 3 months previously, were insulin-naïve, and were able to perform blood glucose self-measurements. Patients were only considered for inclusion if the treating physician had made a decision to use insulin glargine at baseline. Patients were excluded if they had received prior treatment with insulin, sulfonylureas, thiazolidinediones (glitazones), glucagon-like peptide-1 receptor agonists or acarbose within the previous 6 months, had experienced episodes of severe hypoglycemia during the course of the disease (blood glucose $<56 \mathrm{mg} / \mathrm{dL}$ or $<3.1 \mathrm{mmol} / \mathrm{L}$ ), or had a history of alcohol or drug abuse, or dementia, or a general inability to comply with the study requirements. Further, patients with a contraindication to insulin glargine were excluded. On the other hand, we did not stipulate specific contraindications for metformin or DPP-4 inhibitors.

\section{Outcome measures}

The principal outcome measures for the study were mean changes in $\mathrm{HbA}_{1 \mathrm{c}}$, and the proportion of patients reaching an $\mathrm{HbA}_{1 \mathrm{c}}<6.5 \%$ or $<7.0 \%$ from the start of treatment with insulin glargine to the end of the 20 -week observation period. Further, changes in fasting plasma glucose and the proportion of patients achieving a fasting plasma glucose $<100 \mathrm{mg} / \mathrm{dL}$ $(5.6 \mathrm{mmol} / \mathrm{L})$ were analyzed.

Secondary outcome measures were: achievement of individualized treatment goals for fasting plasma glucose; mean change in insulin dose per day and number of adjustments; mean change in numbers of daily insulin injections; changes in timing of administration of insulin; mean change in metformin dose; mean change in body weight; use of blood glucose test strips; and consumption of pen needles per day and per month at endpoint. The specific DPP-4 inhibitor and its dose were not recorded. 
Safety parameters were: incidence of confirmed symptomatic hypoglycemia with blood glucose levels $\leq 70 \mathrm{mg} / \mathrm{dL}$ ( $3.9 \mathrm{mmol} / \mathrm{L})$; incidence of confirmed severe hypoglycemia with blood glucose levels $<56 \mathrm{mg} / \mathrm{dL}(3.1 \mathrm{mmol} / \mathrm{L})$; and the incidence of other spontaneously reported adverse events, such as dizziness, erysipelas, hyperhidrosis, weight gain, and convulsions, classified by severity.

\section{Statistics}

Power calculations showed that about 1,600 patients were needed to be able to answer the predefined primary research questions. This number was calculated based on the assumption of a normally distributed $\mathrm{HbA}_{1 \mathrm{c}}$ decrease of $0.4 \% \pm 1.2 \%$, with a $95 \%$ confidence interval (CI) ranging from $0.341 \%$ to $0.459 \%$. A normally distributed fasting plasma glucose decrease of $20 \pm 60 \mathrm{mg} / \mathrm{dL}$ would have a $95 \% \mathrm{CI}$ ranging from $17.06 \mathrm{mg} / \mathrm{dL}$ to $22.94 \mathrm{mg} / \mathrm{dL}$. An observed response rate of $25 \%, 50 \%$, and $75 \%$ would result in $95 \%$ CIs of $22.9 \%-27.1 \%, 48.1 \%-51.9 \%$, and $72.9 \%-77.1 \%$, respectively. Adverse events occurring in one of 534 patients were determined to be observable with a probability of $95 \%$ and those occurring in one of 1,000 patients (eg, hypoglycemia) with a probability of $80 \%$.

Double data entry was done using DMSys ${ }^{\circledR}$ version 5.1 (Sigmasoft International, Naples, FL, USA). A comparison with the source documentation was performed at 21 sites (3.23\% of all sites). All patients documented were regarded as the safety set, and all patients complying with the selection criteria as the efficacy set. Because selected variables were missing in some patients, we considered only the subsets with available data, as indicated in the tables for calculating proportions. Statistical analysis of all collected data was performed using descriptive measures according to a predefined statistical analysis plan. Continuous data were described by the mean \pm standard deviation. Categorical data were described using absolute and relative frequencies. The $95 \%$ CIs were reported for the mean changes in $\mathrm{HbA}_{1 \mathrm{c}}$, fasting plasma glucose, and for other estimated parameters. Data were evaluated using Statistical Package for the Social Sciences version 15 software (SPSS Inc., Chicago, IL, USA).

\section{Results}

A total of 1,483 patients were documented by 650 officebased physicians (66.5\% general practitioners, $33.0 \%$ internists, and $0.5 \%$ of both professions, with $2.3 \pm 1.5$ patients per center) across Germany on the basis of a representative demographic pattern between January 1, 2010 and January 9, 2012. These patients were considered the safety set. Among these, no prior metformin/DPP-4 inhibitor treatment was recorded in 170 patients, and a further 51 patients were treated with insulin despite not complying with some of the other selection criteria. This resulted in 1,262 patients being available for the efficacy analysis. Table 1 shows the baseline characteristics for these 1,262 patients, who comprised a typical patient population with type 2 diabetes mellitus with respect to age and sex distribution, presence of comorbidities, and blood glucose control. Insulin glargine was initiated, on average, $1.1 \pm 11.2$ days prior to the baseline evaluation at a mean dose of $13.35 \pm 7.04$ units per day.

\section{Mean changes and achievement of target $\mathrm{HbA}_{\mathrm{Ic}}$ and fasting plasma glucose}

Mean $\mathrm{HbA}_{1 \mathrm{c}}$ decreased from $8.51 \%$ to $7.36 \%$, corresponding to a mean change of $-1.15 \% \pm 0.91 \%(95 \% \mathrm{CI}-1.20$ to -1.10 , Table 2). An $\mathrm{HbA}_{1 \mathrm{c}}$ level $<6.5 \%$ was achieved in $8.2 \%$ of patients and a level $<7.0 \%$ in $31.5 \%$. The mean fasting plasma glucose $(n=1,197)$ decreased from $174 \pm 47 \mathrm{mg} / \mathrm{dL}$ to $127 \pm 31 \mathrm{mg} / \mathrm{dL}$, corresponding to a mean change of $-47.3 \pm 44.1 \mathrm{mg} / \mathrm{dL}$ ( $95 \% \mathrm{CI}-49.8$ to -44.8 ). A fasting plasma glucose level $<100 \mathrm{mg} / \mathrm{dL}$ was achieved in $11.9 \%$ of patients. Individualized fasting plasma glucose goals were achieved in $35.9 \%$. This was because actual treatment goals for fasting plasma glucose were slightly higher than $100 \mathrm{mg} / \mathrm{dL}$ (mean fasting plasma glucose goal $117.5 \pm 14.0 \mathrm{mg} / \mathrm{dL} ; 78.2 \%$ between 100 and $<130 \mathrm{mg} / \mathrm{dL}$, Table 3).

Table I Patient demographics $(n=I, 262)$

\begin{tabular}{|c|c|c|}
\hline & n available & Mean \pm SD or $n(\%)$ \\
\hline Age (years) & 1,262 & $64.2 \pm 10.7$ \\
\hline Female sex & 1,258 & $562(44.7)$ \\
\hline Body weight (kg) & 1,227 & $89.6 \pm 16.8$ \\
\hline Body mass index $\left(\mathrm{kg} / \mathrm{m}^{2}\right)$ & 1,260 & $30.76 \pm 5.05$ \\
\hline Diabetes duration $\geq 5$ years & $\mathrm{I}, 255$ & $905(72.1)$ \\
\hline \multicolumn{3}{|l|}{ Blood glucose values } \\
\hline $\mathrm{HbA}_{\mathrm{Ic}}(\%)$ & $\mathrm{I}, 247$ & $8.50 \pm 0.98$ \\
\hline Fasting blood glucose (mg/dL) & $\mathrm{I}, 242$ & $174.0 \pm 46.6$ \\
\hline \multicolumn{3}{|l|}{ Diabetes-related comorbidity* } \\
\hline None & $\mathrm{I}, 255$ & $436(34.7)$ \\
\hline Microalbuminuria & $\mathrm{I}, 225$ & $402(32.8)$ \\
\hline Macroalbuminuria & $\mathrm{I}, 2 \mathrm{I} 5$ & $57(4.7)$ \\
\hline Nephropathy & 1,222 & $175(14.3)$ \\
\hline Retinopathy & 1,217 & $175(14.3)$ \\
\hline Neuropathy & 1,230 & $381(31.0)$ \\
\hline Diabetic foot syndrome & $\mathrm{I}, 225$ & $108(8.8)$ \\
\hline Coronary artery disease & 1,230 & $336(27.3)$ \\
\hline Myocardial infarction & 1,222 & $96(7.9)$ \\
\hline Stroke/transient ischemic attack & $\mathrm{I}, 2 \mid 4$ & $64(5.3)$ \\
\hline Peripheral arterial disease & $\mathrm{I}, 22 \mathrm{I}$ & $122(10.0)$ \\
\hline
\end{tabular}

Note: *Overlap because of multiple comorbidities.

Abbreviations: $\mathrm{HbA}_{1 \mathrm{c}}$, glycosylated hemoglobin; SD, standard deviation. 
Table 2 Primary efficacy measures of $\mathrm{HbA}_{\mathrm{lc}}$ and FPG

\begin{tabular}{|c|c|c|c|c|}
\hline & Post-baseline & End of follow-up & Difference & $95 \% \mathrm{Cl}$ \\
\hline Mean $\mathrm{HbA}_{\mathrm{Ic}}, \%(\mathrm{n}=1,2 \mid 0)$ & $8.5 I \pm 0.8 I$ & $7.36 \pm 0.88$ & $-1.15 \pm 0.91$ & $-1.20 ;-1.10$ \\
\hline $\mathrm{HbA}_{\text {Ic }}$ level $<6.5 \%, \mathrm{n}(\%)(\mathrm{n}=\mathrm{I}, 262)$ & - & $104(8.2)$ & & $6.8 \% ; 9.9 \%$ \\
\hline $\mathrm{HbA}_{\text {Ic }}$ level $<7.0 \%, \mathrm{n}(\%)(\mathrm{n}=1,262)$ & - & $397(31.5)$ & & $28.9 \% ; 34.1 \%$ \\
\hline Mean FPG, $\mathrm{mg} / \mathrm{dL}(\mathrm{n}=\mathrm{I}, 197)$ & $174 \pm 47$ & $|27 \pm 3|$ & $-47.3 \pm 44.1$ & $-49.8 ;-44.8$ \\
\hline$<100 \mathrm{mg} / \mathrm{dL} \mathrm{n}(\%)(\mathrm{n}=1,262)$ & - & $150(11.9)$ & & $10.2 \% ; 13.8 \%$ \\
\hline
\end{tabular}

Abbreviations: $\mathrm{HbA}_{\mathrm{lc}}$, glycosylated hemoglobin; $\mathrm{Cl}$, confidence interval; $\mathrm{FPG}$, fasting plasma glucose.

\section{Secondary outcomes}

During the approximately 20 weeks of treatment, the dose of insulin glargine was initiated at $13.43 \pm 7.11$ units/day and then increased to $20.39 \pm 9.54$ units/day at the end of followup, corresponding to a mean change of $6.96 \pm 7.70$ units/day on treatment (Table 3 ). The frequency of insulin dose adjustments decreased during the observation period. In the first month, a mean of $1.35 \pm 1.24$ insulin adjustments took place, with a decrease in months $2(1.04 \pm 0.93), 3(0.72 \pm 0.87)$, $4(0.52 \pm 0.79)$, and $5(0.39 \pm 0.75)$.

Insulin glargine was injected in the majority of patients once a day post baseline $(96.59 \%)$ and after 20 weeks of observation (90.33\%). Only $1.82 \%$ and $2.93 \%$ of the patients, respectively, injected insulin glargine twice daily. Preferred administration times were at bedtime ( $42.63 \%$ post baseline and $40.10 \%$ after 20 weeks) and in the evening (36.69\% and $34.31 \%$, respectively, Table 3 ).

\section{Safety}

A total of 29 adverse events occurred in 13 patients $(0.88 \%$, Table 4$)$. Relevant adverse events were hypoglycemia $(0.20 \%)$ and dizziness, erysipelas, hyperhidrosis, and weight increase $(0.13 \%$ each). Serious adverse events were observed for $0.40 \%(n=6)$ of patients. In two patients with a total of five events, a causal relationship with insulin glargine could not be excluded. Reported adverse drug reactions were hypoglycemia $(0.13 \%)$, convulsions, hyperhidrosis, and weight increase $(0.07 \%$ each). Serious adverse drug reactions were observed in one patient (hypoglycemia and convulsions, 0.07\%). One patient died during the study for reasons unrelated to insulin glargine treatment. Hypoglycemia (blood glucose $\leq 70 \mathrm{mg} / \mathrm{dL}$ ) was observed in 29 patients $(2.30 \%)$, of whom six $(0.48 \%)$ occurred during the night and four $(0.32 \%)$ were considered to be severe (blood glucose $<56 \mathrm{mg} / \mathrm{dL}$ ). The

Table 3 Secondary outcome measures

\begin{tabular}{|c|c|c|c|c|}
\hline & Post-baseline & End of follow-up & Difference & $95 \% \mathrm{Cl}$ \\
\hline \multicolumn{5}{|l|}{ Individual FPG treatment goals $(n=1,208)$} \\
\hline$<100 \mathrm{mg} / \mathrm{dL}, \mathrm{n}(\%)$ & - & $6 \mathrm{I}(5.0)$ & - & $3.9 \% ; 6.4 \%$ \\
\hline 100 to $<130 \mathrm{mg} / \mathrm{dL}, \mathrm{n}(\%)$ & - & $945(78.2)$ & - & $75.8 \% ; 80.5 \%$ \\
\hline$\geq 130 \mathrm{mg} / \mathrm{dL}, \mathrm{n}(\%)$ & - & $202(16.7)$ & - & $14.7 \% ; 18.9 \%$ \\
\hline Mean insulin dose per day $(n=I, \mid 80)$ & 13.43 & 20.39 & $+6.96 \pm 7.70$ & $6.52 ; 7.40$ \\
\hline \multicolumn{5}{|l|}{ Insulin injection $(n=I, 262)$} \\
\hline Once daily insulin injection, $\mathrm{n}(\%)$ & $1,219(96.59)$ & $\mathrm{I}, \mathrm{I} 40(90.33)$ & - & - \\
\hline \multicolumn{5}{|l|}{ Administration time point } \\
\hline Morning, n (\%) & $201(15.93)$ & $189(14.98)$ & - & - \\
\hline Lunch, n (\%) & $17(1.35)$ & $12(0.95)$ & - & - \\
\hline Evening, $\mathrm{n}(\%)$ & $463(36.69)$ & $433(34.31)$ & - & - \\
\hline Bedtime, n (\%) & $538(42.63)$ & $506(40.10)$ & - & - \\
\hline Twice daily, $\mathrm{n}(\%)$ & $23(1.82)$ & $37(2.93)$ & - & - \\
\hline No data, $\mathrm{n}(\%)$ & $20(1.58)$ & $85(6.74)$ & - & - \\
\hline Mean metformin dose, $m g(n=I, 24 I)$ & I,888.56 & I,88I.4| & $-7.15 \pm 145.19$ & $-15.24 ; 0.94$ \\
\hline Mean body weight, $\mathrm{kg}(\mathrm{n}=\mathrm{I}, 227)$ & $89.56 \pm 16.8$ & $88.58 \pm 16.3$ & $-0.98 \pm 3.90$ & $-1.19 ;-0.76$ \\
\hline $\begin{array}{l}\text { Mean consumption of blood glucose test } \\
\text { strips per month at } 20 \text { weeks }(n=1,067)\end{array}$ & $41.59 \pm 37.53$ & $45.06 \pm 36.30$ & $+3.47 \pm 36.46$ & $1.28 ; 5.66$ \\
\hline $\begin{array}{l}\text { Mean consumption of pen needles per } \\
\text { month at } 20 \text { weeks }(n=1,183)\end{array}$ & - & $24.58 \pm 14.75$ & - & $23.74 ; 25.42$ \\
\hline
\end{tabular}

Abbreviations: $\mathrm{Cl}$, confidence interval; FPG, fasting plasma glucose. 
Table 4 Safety and rates of hypoglycemia

\begin{tabular}{|c|c|c|c|}
\hline & $\mathrm{n}$ available & $\begin{array}{l}\text { AE rate, } \\
\text { n (\%) }\end{array}$ & $\begin{array}{l}\text { ADR rate, } \\
\text { n (\%) }\end{array}$ \\
\hline \multirow[t]{2}{*}{ Any event } & $\mathrm{I}, 483$ & $13(0.88)$ & $2(0.13)$ \\
\hline & & [29 events] & [5 events] \\
\hline Hypoglycemia & $\mathrm{I}, 483$ & $3(0.20)$ & $2(0.13)$ \\
\hline Dizziness & $\mathrm{I}, 483$ & $2(0.13)$ & 0 \\
\hline Erysipelas & I,483 & $2(0.13)$ & 0 \\
\hline Hyperhidrosis & $\mathrm{I}, 483$ & $2(0.13)$ & I (0.07) \\
\hline Weight gain & $\mathrm{I}, 483$ & $2(0.13)$ & I (0.07) \\
\hline Convulsion & $\mathrm{I}, 483$ & 0 & I (0.07) \\
\hline Serious events & $\mathrm{I}, 483$ & $6(0.40)$ & I (0.07) \\
\hline \multirow[t]{2}{*}{ Death } & $\mathrm{I}, 483$ & $\mathrm{I}(0.07)$ & 0 \\
\hline & n available & \multicolumn{2}{|c|}{$\begin{array}{l}\text { Hypoglycemia, } n(\%) \\
\text { or mean } \pm \text { SD }\end{array}$} \\
\hline Confirmed hypoglycemia & $\mathrm{I}, 243$ & \multicolumn{2}{|l|}{$29(2.33)$} \\
\hline Mean number of episodes & $\mathrm{I}, 238$ & \multicolumn{2}{|l|}{$1.88 \pm 1.03$} \\
\hline Nocturnal hypoglycemia & $\mathrm{I}, 240$ & \multicolumn{2}{|l|}{$6(0.48)$} \\
\hline Mean number of episodes & $\mathrm{I}, 240$ & \multicolumn{2}{|l|}{$1.67 \pm 0.82$} \\
\hline Severe hypoglycemia & $|, 24|$ & \multicolumn{2}{|l|}{$4(0.32)$} \\
\hline Mean number of episodes & $\mathrm{I}, 24 \mathrm{I}$ & \multicolumn{2}{|l|}{$1.0 \pm 0.0$} \\
\hline
\end{tabular}

Abbreviations: $A E$, adverse event; $A D R$, adverse drug reaction; SD, standard deviation.

mean number of confirmed hypoglycemic episodes was $1.88 \pm 1.03(\mathrm{n}=24)$.

\section{Treatment satisfaction}

At the end of the 20-week observation period, $92.6 \%$ of patients were continuing their insulin glargine treatment (no data available for $4.2 \%$ ). Physicians indicated that the main reason for discontinuation of insulin glargine was insufficient blood glucose control $(\mathrm{n}=17,1.35 \%)$. One patient discontinued because of adverse events. For the other patients $(n=15)$, no reason for discontinuation was recorded.

\section{Discussion}

The role of insulin in the treatment of patients with type 2 diabetes has evolved considerably within the last decade from being a last resort treatment to a first-line drug that may be used at any stage of the disease. Early treatment with insulin is thought to protect the beta-cell from the consequences of long-term exposure to hyperglycemia. ${ }^{11}$ Early initiation, as suggested by the recent results of the ORIGIN (Outcome Reduction with an Initial Glargine Intervention) trial, ${ }^{12}$ is powerful in improving long-term glycemic control, and may prevent or delay chronic complications in patients with type 2 diabetes. ${ }^{13-16}$ In real-world clinical practice however, timely initiation of insulin is often hampered by concerns about weight gain, hypoglycemia, and the patient's fear of injections. ${ }^{17}$
The aim of this noninterventional study in clinical practice was to observe and analyze the use of insulin glargine added to a baseline combination treatment of metformin and a DPP-4 inhibitor in patients with type 2 diabetes mellitus. We found an $\mathrm{HbA}_{1 \mathrm{c}}$ reduction of $1.15 \%$ and a decrease in fasting plasma glucose of $47.25 \mathrm{mg} / \mathrm{dL}$, with a low frequency of hypoglycemic episodes $(2.30 \%$ any and $0.32 \%$ severe $)$ over a treatment duration of 20 weeks. Body weight did not increase; on the contrary, it was reduced by about $1 \mathrm{~kg}$. Adverse drug reactions were recorded in two patients $(0.13 \%)$ and serious adverse drug reactions in one patient. Treatment satisfaction was high, with at least $92.6 \%$ of patients continuing their treatment beyond the observation period.

These results are in agreement with previous randomized controlled trial results suggesting that the complementary action of long-acting insulin and incretin-based treatment strategies on a background metformin therapy is both effective and well tolerated, in that it is associated with a low rate of hypoglycemia and comes without weight gain. ${ }^{3-6}$ In a previous randomized controlled trial, ${ }^{3}$ when insulin detemir was added to a combination of sitagliptin and metformin versus a combination of sitagliptin, metformin, and a sulfonylurea, a mean $\mathrm{HbA}_{1 \mathrm{c}}$ decrease of $1.44 \%$ was observed within 26 weeks, and fasting plasma glucose decreased by $66.3 \mathrm{mg} / \mathrm{dL}(3.7 \mathrm{mmol} / \mathrm{L})$ when basal insulin was added. Small decreases were seen in body weight and body mass index. Rates of hypoglycemia were low (1.3 episodes per year), with no severe episodes recorded.

Insulin is frequently used when $\mathrm{HbA}_{1 \mathrm{c}}$ values rise above $7.5 \%$ or $8.0 \%$ despite multiple combinations of oral antidiabetic drugs. This is in contrast with a recent study in patients with type 2 diabetes who were inadequately controlled by metformin, in whom the early use of basal insulin was associated with a significant improvement in residual pancreatic beta-cell function. ${ }^{18}$ In the EARLY (Early Basal Insulin Therapy under Real-Life Conditions in Type 2 Diabetics $)^{19}$ observational trial, the use of basal insulin glargine in patients on maximal doses of metformin reduced $\mathrm{HbA}_{1 \mathrm{c}}$ from $8.7 \%$ to $7.4 \%$ within 24 weeks, with a low risk of hypoglycemia and slightly decreased weight. Multivariate analysis demonstrated better results in patients with a shorter history of diabetes and a higher $\mathrm{HbA}_{1 \mathrm{c}}$ at baseline. ${ }^{19,20}$ Fonseca et al confirmed these results in a recent meta-analysis demonstrating the benefits of early addition of basal insulin to metformin compared with a prior combination of metformin and a sulfonylurea. ${ }^{21}$ Patients on metformin monotherapy and add-on insulin 
glargine achieved a greater reduction in $\mathrm{HbA}_{1 \mathrm{c}}$, with lower rates of severe hypoglycemia and less weight gain compared with those on metformin plus sulfonylurea at baseline.

The design of this study, documenting real world clinical practice, has some inherent limitations. An important aspect to be considered is its nonrandomized and noncontrolled design. This may have led to a selection bias towards patients in whom a low rate of complications may be expected. Further, treatment effects and complications such as hypoglycemia cannot be linked to a particular treatment. Because of the lack of a control group taking placebo or an active substance such as a sulfonylurea, the impact of a closer surveillance within this observation cannot be quantified. Another aspect is the rather poor control at baseline with a mean $\mathrm{HbA}_{1 \mathrm{c}}$ of $8.5 \%$ and fasting plasma glucose of $174 \mathrm{mg} / \mathrm{dL}(9.7 \mathrm{mmol} / \mathrm{L})$, which is similar to the study reported by Hollander et al. ${ }^{3}$ Because of the high $\mathrm{HbA}_{1 \mathrm{c}}$ at baseline, the relative contribution of fasting plasma glucose versus postprandial plasma glucose to $\mathrm{HbA}_{1 \mathrm{c}}$ may be increased, ${ }^{22}$ favoring the action of insulin.

\section{Conclusion}

The results of this observational study showed that insulin glargine, when added to a combination of metformin and a DPP-4 inhibitor, resulted in a significant and clinically relevant improvement of glycemic control. This intervention did not interfere with the drug profile of the DPP-4 inhibitors, resulting in neutral effects on weight and low rates of hypoglycemia. This approach was shown to be useful, effective, and safe in daily clinical practice when treatment has to be intensified in patients who are not well controlled on oral antidiabetic drugs. These results may further help to promote the timeliness of establishing insulin therapy in these patients.

\section{Author contributions}

JS, KP, and PB were involved in the analysis and interpretation of the data. JS and PB drafted the first version of the manuscript and KP revised it for important intellectual content. All authors approved the final version for publication.

\section{Disclosure}

The analysis was funded by Sanofi, Berlin, Germany. JS has been on speaker's bureaus for AstraZeneca, Bristol-Myers Squibb, Bayer Healthcare, Berlin Chemie AG, Eli Lilly \& Co, GlaxoSmithKline, Lifescan Inc, Merck Sharp and Dohme, Novartis, Novo Nordisk, Pfizer Inc, Sanofi, and Takeda. PB has received research funding and honoraria for consultancy from AstraZeneca, Bristol-Myers Squibb, Novartis, and Sanofi, and received financial support for preparation of this paper (eg, data analysis and drafting). KP is an employee of Sanofi, Berlin.

\section{References}

1. Esposito K, Cozzolino D, Bellastella G, et al. Dipeptidyl peptidase4 inhibitors and $\mathrm{HbA}_{1 \mathrm{c}}$ target of $<7 \%$ in type 2 diabetes: meta-analysis of randomized controlled trials. Diabetes Obes Metab. 2011;13(7): 594-603.

2. Deacon CF, Mannucci E, Ahren B. Glycaemic efficacy of glucagonlike peptide-1 receptor agonists and dipeptidyl peptidase- 4 inhibitors as add-on therapy to metformin in subjects with type 2 diabetes - a review and meta analysis. Diabetes Obes Metab. 2012;14(8):762-767.

3. Hollander P, Raslova K, Skjoth TV, Rastam J, Liutkus JF. Efficacy and safety of insulin detemir once daily in combination with sitagliptin and metformin: the TRANSITION randomized controlled trial. Diabetes Obes Metab. 2011;13(3):268-275.

4. Rosenstock J, Rendell MS, Gross JL, Fleck PR, Wilson CA, Mekki Q. Alogliptin added to insulin therapy in patients with type 2 diabetes reduces $\mathrm{HbA}(1 \mathrm{C})$ without causing weight gain or increased hypoglycaemia. Diabetes Obes Metab. 2009;11(12):1145-1152.

5. Vilsboll T, Rosenstock J, Yki-Jarvinen H, et al. Efficacy and safety of sitagliptin when added to insulin therapy in patients with type 2 diabetes. Diabetes Obes Metab. 2010;12(2):167-177.

6. Arnolds S, Dellweg S, Clair J, et al. Further improvement in postprandial glucose control with addition of exenatide or sitagliptin to combination therapy with insulin glargine and metformin: a proof-of-concept study. Diabetes Care. 2010;33(7):1509-1515.

7. Ligthelm RJ, Borzi V, Gumprecht J, Kawamori R, Wenying Y, Valensi P. Importance of observational studies in clinical practice. Clin Ther. 2007;29(6 Pt 1):1284-1292.

8. Baxter MA. The role of new basal insulin analogues in the initiation and optimisation of insulin therapy in type 2 diabetes. Acta Diabetol. 2008;45(4):253-268.

9. Owens DR, Bolli GB. Beyond the era of NPH insulin - long-acting insulin analogs: chemistry, comparative pharmacology, and clinical application. Diabetes Technol Ther. 2008;10(5):333-349.

10. Mullins P, Sharplin P, Yki-Jarvinen H, Riddle MC, Haring HU. Negative binomial meta-regression analysis of combined glycosylated hemoglobin and hypoglycemia outcomes across eleven Phase III and IV studies of insulin glargine compared with neutral protamine Hagedorn insulin in type 1 and type 2 diabetes mellitus. Clin Ther. 2007;29(8): 1607-1619.

11. Glaser B, Cerasi E. Early intensive insulin treatment for induction of long-term glycaemic control in type 2 diabetes. Diabetes Obes Metab. 1999;1(2):67-74.

12. ORIGIN trial investigators, Gerstein HC, Bosch J, et al. Basal insulin and cardiovascular and other outcomes in dysglycemia. $N$ Engl J Med. 2012;367(4):319-328.

13. Holman RR, Paul SK, Bethel MA, Matthews DR, Neil HA. 10-year follow-up of intensive glucose control in type 2 diabetes. NEngl J Med. 2008;359(15):1577-1589.

14. UK Prospective Diabetes Study (UKPDS) Group. Intensive bloodglucose control with sulphonylureas or insulin compared with conventional treatment and risk of complications in patients with type 2 diabetes (UKPDS 33). Lancet. 1998;352(9131):837-853.

15. Control G, Turnbull FM, Abraira C, et al. Intensive glucose control and macrovascular outcomes in type 2 diabetes. Diabetologia. 2009;52(11): 2288-2298.

16. Ray KK, Seshasai SR, Wijesuriya S, et al. Effect of intensive control of glucose on cardiovascular outcomes and death in patients with diabetes mellitus: a meta-analysis of randomised controlled trials. Lancet. 2009;373(9677):1765-1772.

17. Horne PJ, Erjavec M. Do infants show generalized imitation of gestures? J Exp Anal Behav. 2007;87(1):63-87. 
18. Pennartz C, Schenker N, Menge BA, Schmidt WE, Nauck MA, Meier JJ. Chronic reduction of fasting glycemia with insulin glargine improves first- and second-phase insulin secretion in patients with type 2 diabetes. Diabetes Care. 2011;34(9):2048-2053.

19. Hanefeld M, Fleischmann H, Landgraf W, Pistrosch F. EARLY Study: Early Basal Insulin Therapy under Real-Life conditions in type 2 Diabetics. Diabetes, Stoffwechsel und Herz. 2012;21(2):91-97.

20. Hanefeld M, Fleischmann H, Schiffhorst G, Bramlage P. Predictors of response to early basal insulin treatment in patients with type-2 diabetes - the EARLY experience. Diab Technol Ther. 2013.
21. Fonseca V, Gill J, Zhou R, Leahy J. An analysis of early insulin glargine added to metformin with or without sulfonylurea: impact on glycaemic control and hypoglycaemia. Diabetes Obes Metab. 2011;13(9): 814-822.

22. Monnier L, Lapinski H, Colette C. Contributions of fasting and postprandial plasma glucose increments to the overall diurnal hyperglycemia of type 2 diabetic patients: variations with increasing levels of $\mathrm{HbA}(1 \mathrm{c})$ Diabetes Care. 2003;26(3):881-885.

\section{Publish your work in this journal}

Vascular Health and Risk Management is an international, peerreviewed journal of therapeutics and risk management, focusing on concise rapid reporting of clinical studies on the processes involved in the maintenance of vascular health; the monitoring, prevention and treatment of vascular disease and its sequelae; and the involvement of metabolic disorders, particularly diabetes. This journal is indexed on PubMed Central and MedLine. The manuscript management system is completely online and includes a very quick and fair peer-review system, which is all easy to use. Visit http://www.dovepress.com/ testimonials.php to read real quotes from published authors.

Submit your manuscript here: http://www.dovepress.com/vascular-health-and-risk-management-journal 